\title{
A national survey of AIRO (Italian Association of Radiation Oncology) brachytherapy (Interventional Radiotherapy) study group
}

\author{
Rosa Autorino, MD, PhD', Lisa Vicenzi, MD², Luca Tagliaferri, MD, PhD', Carlo Soatti, MD³, Prof. Gyeorgy Kovacs, MD, PhD, \\ Cynthia Aristei, MD5 \\ IFondazione Policlinico Universitario A. Gemelli IRCCS, Dipartimento Scienze Radiologiche, Radioterapiche ed Ematologiche, Roma, Italy, \\ ${ }^{2}$ Department of Oncology and Radiotherapy, Azienda Ospedaliero Universitaria Ospedali Riuniti, Ancona, Italy, ${ }^{3}$ Department of Oncology \\ and Radiotherapy, Azienda Ospedaliero Lecco, Italy, ${ }^{4}$ Interdisciplinary Brachytherapy Unit, University of Lübeck - University Hospital S-H. \\ Campus Lübeck, Germany, "5epartment of Surgery and Biomedical Science, Section of Radiation Oncology. University of Perugia \\ and Perugia General Hospital, Perugia, Italy
}

\begin{abstract}
Purpose: To review brachytherapy resources and to explore current practice patterns in Italy.

Material and methods: In 2016, on behalf of the Italian Association of Radiation Oncology (AIRO), the Brachytherapy Study Group proposed conducting a survey in order to identify brachytherapy practice patterns. An electronic questionnaire was sent to all radiotherapy centres in Italy, asking for: 1. General information on the Radiation Oncology Centre (affiliation, whether brachytherapy was delivered or not); 2. Brachytherapy equipment and human resources; 3. Brachytherapy procedures; 4 . Brachytherapy assessment (number of patients treated annually, treated sites, and different modalities of treatments).
\end{abstract}

Results: A total of 66 questionnaires were returned (33.5\% of all brachytherapy centers in Italy), out of which 48 (74\%) from non-academic hospitals, $6(10 \%)$ from academic hospitals, and $12(16 \%)$ from private institutions. Most centers (84\%) had only one brachytherapy machine; $44 \%$ did not deliver brachytherapy treatments or delivered less than demanded because of the lack of staff or expertise, need of modernization, or other reasons. The majority of treatments were administered to outpatients for gynecological tumors.

Conclusions: This survey illustrates the current status of brachytherapy in Italy and should encourage collaboration to develop, implement, and monitor its use when appropriate.

J Contemp Brachytherapy 2018; 10, 3: 254-259 DOI: https://doi.org/10.5114/jcb.2018.76981

Key words: AIRO (Italian Association of Radiation Oncology) brachytherapy, survey.

\section{Purpose}

Modern interest in brachytherapy as a sole therapy or in combined treatment schedules for cancer malignancies became accessible for difficult anatomic sites with small, highspecific activity remote afterloading sources, new catheter design, and advanced imaging systems, such as cross-section computed tomography (CT) or magnetic resonance imaging (MRI). These technical developments have continually improved the quality and efficacy of treatments [1,2].

Brachytherapy delivers very high doses to target volumes, while sparing the neighbouring organs at risk. It has the potential to increase cure and organ preservation rates, while being associated with low-to-moderate toxicity. Its optimal use, however, is operator-dependent as it requires radiation oncologists with complex, advanced technical skills who are knowledgeable about cancer-related surgical procedures. Furthermore, a well-functioning multi- disciplinary team and specifically trained inter-disciplinary staff are essential since different specialists need to cooperate and coordinate their work closely.

Here, we describe a survey that was conducted in Italian Radiation Oncology Centres with the aim of outlining the current status of brachytherapy infrastructure and care patterns in Italy.

\section{Material and methods}

The 22 survey questions were set up by the Brachytherapy Study Group on behalf of the Italian Association of Radiation Oncology (AIRO) and distributed online using www.surveymonkey.com. The online questionnaire was open for completion between June and September 2016. All heads of 197 radiation oncology centres in Italy were individually contacted by e-mail and invited to participate in the study, asking for an expert in brachytherapy
Address for correspondence: Rosa Autorino, MD, PhD, Department of Radiation Oncology Gemelli-ART, Catholic University, Italy, L.go A. Gemelli, 0168 Rome, Italy, phone: + 39 630155339, • e-mail: rosa_autorino@yahoo.it
Received: 06.02.2018

Accepted: 12.06.2018

Published: 30.06.2018 
to answer the survey questions. When a radiation oncology centre did not deliver brachytherapy treatments, the centre answered only the five questions in section 1 .

Questionnaire sections are summarized as follow:

Section 1 (Q1-5): background information

Radiation oncology centre was asked for its address and affiliation (i.e., national health service hospital, accredited private hospital, private hospital, or university hospital) and whether brachytherapy was delivered or not.

Section 2 (Q6-12): brachytherapy equipment and human resources

Questions focussed on the number and model of brachytherapy units, whether they were used or not, treatment planning systems (TPS), and how many physicians were engaged in brachytherapy.

Section 3 (Q13-18): brachytherapy procedures

Questions enquired about other medical specialists that were involved in brachytherapy treatment, whether protocols were in place to treat brachytherapy-related pain, whether the radiation oncology centre was equipped with a dedicated bunker, operating theatre, and CT-simulator room.

Section 4 (Q 19-21): brachytherapy assessment

Questions investigated how many patients were treated with brachytherapy annually and what percentage they constituted of the total number of patients in the radiation oncology centre. They also inquired about how many brachytherapy treatments were delivered annually in the centre, to which tumor sites, the type of brachytherapy treatments (low-dose-rate - LDR; high-dose-rate HDR; pulsed-dose-rate - PDR), whether the treatment planning was $2 \mathrm{D}$ or $3 \mathrm{D}$, and whether $\mathrm{CT}$ scans or MRI were used for contouring.

\section{Results}

A total of $66 / 197$ (33\%) Italian radiation oncology centres accessed the online survey and replied to the questionnaire over a 4-month period.

Section 1: background information

Most participating physicians worked in national health service hospitals (74\%), while private or univer- sity hospitals accounted for $16 \%$ and $10 \%$ of responders, respectively.

Section 2: brachytherapy equipment and human resources

$43 / 66$ responding radiation oncology centres declared they were equipped with brachytherapy devices. Almost half (19 centres) did not deliver brachytherapy treatments or delivered less than demanded because of lack of personnel or expertise, the need to update equipment, etc. (Figure 1). One-third of radiation oncologists in each center was engaged in brachytherapy. Only 1 brachytherapy unit was found in $84 \%$ of radiation oncology centres, while 2 and 3 units were reported by $11 \%$ and $5 \%$, respectively. Most centres (89\%) used microselectron HDR with Oncentra TPS (ELEKTA, Sweden). The other $11 \%$ used 126-RU or 125-Iodine plaque brachytherapy for choroidal melanoma, with plaque simulator TPS.

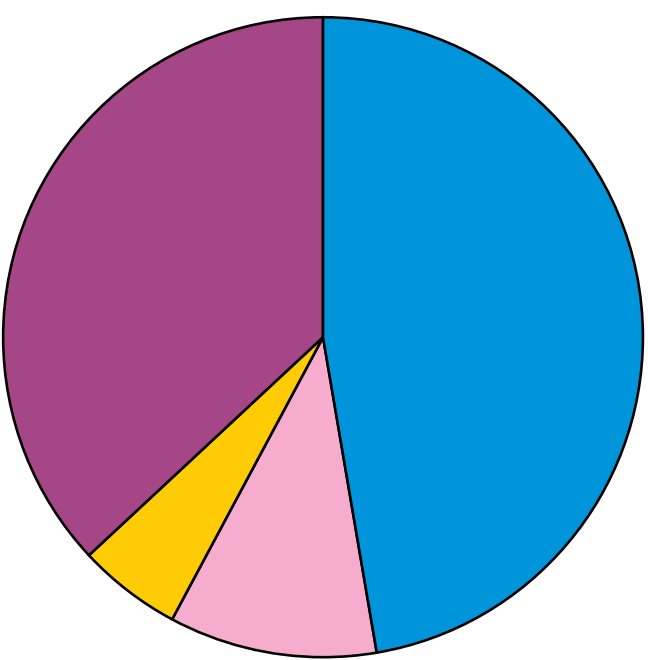

$\square$ Lack of personel (47\%)

$\square$ Lack of expertise $(11 \%)$

$\square$ Need to update equipment $(5 \%)$

$\square$ CPSTS/TIME consuming (7\%)

$\square$ Not specified $(30 \%)$

Fig. 1. Reasons for not using available brachytherapy equipment

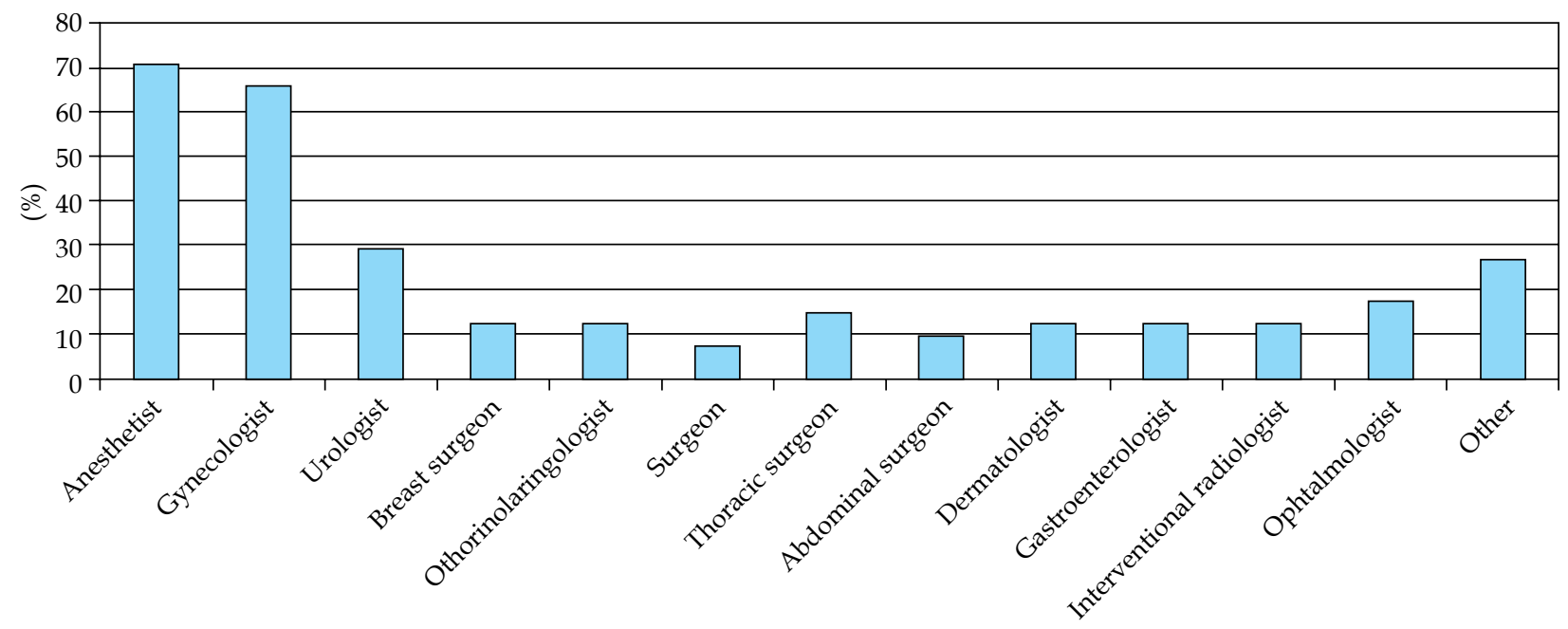

Fig. 2. Specialists involved in brachytherapy 


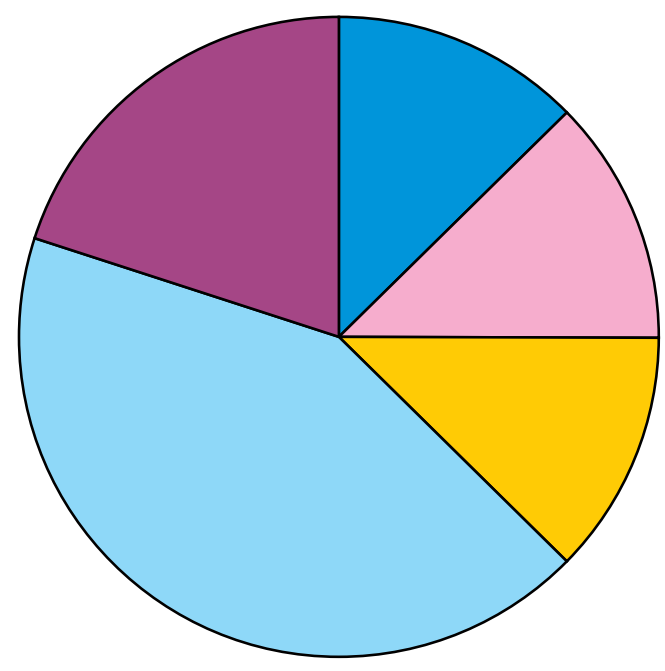

$\square$ Operating theater of specia $(12.5 \%)$

$\square$ Radiotherapy medical room $(12.5 \%)$

$\square$ CT-stimulator room $(12.5 \%)$

$\square$ Brachytherapy treatment room $(42.5 \%)$

$\square$ Other (specify) (20\%)

Fig. 3. Places dedicated for brachytherapy delivery

\section{Section 3: brachytherapy procedures}

Brachytherapy treatment often involved other medical specialists, as reported in Figure 2. Since many radiation oncology centers treated only gynecological cancers with brachytherapy, anesthesists and gynecologists were the most frequent part of the multi-disciplinary team. Analgesia was prescribed for $73 \%$ of patients who underwent brachytherapy.

Almost $50 \%$ of radiation oncology centers reported they had a dedicated brachytherapy operating theatre; $13 \%$ used operating theatres of other specialists, according to disease location; $13 \%$ used the CT-simulator room, and $13 \%$ used a treatment room in the centre (Figure 3).

Section 4: brachytherapy assessment

A median of $37 \%$ patients in each centre were treated with brachytherapy. The median number of treatments was 271 per year (range, 5-1,013). Brachytherapy was delivered to out-patients in $45 \%$ of cases, in day-hospital patients in $13 \%$, and to in-patients in $21 \%$. HDR units were available in 33 centres, LDR afterloaders were present in 3 , both HDR and LDR afterloader were present in 4, and HDR were found with PDR units in 3 places.

Table 1 summarizes distribution of brachytherapy treatments according to disease site in all responding radiation oncology centres. Although 2D planning by X-rays is still used in a few centers, in most of them, a CT-based approach is used to define target volumes. MRI is available in very few centres, and is used mainly for contouring targets and organs at risk in patients with gynecological tumours.

\section{Discussion}

This study designed a national survey to investigate current brachytherapy status in Italian radiation oncology centres. Although the term "brachytherapy" is com- monly used, the term "interventional radiotherapy" is spreading in Italy. In fact, the Italian Association of Radiation Oncology has recently changed the name of the Brachytherapy Working Group to the "Brachytherapy, Interventional Radiotherapy, Intraoperative Radiotherapy Working Group".

The major limit of the present survey was that only one-third (66/197) of Italian radiation oncology centres replied to the questionnaire. Even though this response rate compares with other surveys, it cannot be taken as representative of Italian practice. However, one might speculate that low response rate was linked to few Italian radiation oncology centres offering brachytherapy, which may have been more interested in responding to questions.

For many years, intensity-modulated radiotherapy and stereotactic radiotherapy were preferred to brachytherapy in Italy since they are non-invasive, and because the Italian National Health Service pays more for these advanced external beam radiotherapy techniques. The decline in brachytherapy led to a vicious circle of fewer cases being treated, inadequate mantenance of brachytherapy skills in community and academic centers, and limited training for radiation oncology residents.

Despite this, technical developments, advanced imaging systems, networking, and multi-disciplinary approaches led to the development of high-quality brachytherapy teams encompassing anaesthesists and specialists according to cancer location (gynaecologists, urologists, ENT specialists). Nearly two-thirds of Italian radiation oncology centres are equipped with modern HDR brachytherapy systems, in line with three regions in the Northern Italy [3] and the rest of Europe $[4,5]$. HDR technology has replaced the long tradition of LDR brachytherapy because of advantages such as out-patient treatment, patient convenience, complete radiation protection for personnel, and better individual dose volume optimization due to dwelling source technology, so that modulation of dwell positions and times, can control dose distribution. Furthermore, the use of 192-iridium as the irradiation source with small-diameter and flexible applicators can target body sites that would not otherwise be conveniently accessible.

The mean number of patients who received brachytherapy per year in Italian centres was estimated to be close to the European average of 100 annually [5,6]. Over $50 \%$ of Italian centres used brachytherapy only or mostly for treating gynecological cancers, confirming the results of the European survey, which observed that gynaecological brachytherapy was the most common application. In the European and Korean scenarios, brachytherapy was used almost exclusively as primary treatment of inoperable endometrial and cervical tumors or as post-hysterectomy therapy for high-risk tumours $[7,8,9,10,11]$.

Although both prostate and breast brachytherapy applications were reported to be increasing in Europe [5], the trend was different in Italy. In fact, few Italian centres provided brachytherapy for prostate cancer, even though evidence from long-term studies supported its use [12], as LDR with seeds and HDR monotherapy were associated with similar biochemical control rates as surgery or external beam radiotherapy and fewer side-effects. Consequently, physicians should be more inclined to rec- 
Table 1. Number of Italian brachytherapy centres, patients and planning, and delivery techniques for diverse tumour sites

\begin{tabular}{|c|c|c|c|c|c|c|c|c|c|c|}
\hline \multirow[t]{2}{*}{ Site } & \multirow{2}{*}{$\begin{array}{l}\text { RT } \\
\text { Centre } \\
(n)\end{array}$} & \multirow[t]{2}{*}{$\begin{array}{l}\text { Patients } \\
\text { per year }\end{array}$} & \multirow[t]{2}{*}{$\operatorname{HDR}(n)$} & \multirow[t]{2}{*}{$\operatorname{PDR}(n)$} & \multirow[t]{2}{*}{$\operatorname{LDR}(n)$} & \multicolumn{2}{|c|}{$\begin{array}{l}\text { Planning } \\
\text { technique }\end{array}$} & \multicolumn{2}{|c|}{ Treatments per year } & \multirow[t]{2}{*}{$\begin{array}{l}\text { Imaging for } \\
\text { planning }\end{array}$} \\
\hline & & & & & & $2 \mathrm{D}$ & $3 D$ & Radical & Palliative & \\
\hline Vagina & 31 & 1089 & 1041 & 48 & 0 & 3 & 28 & 1071 & 18 & $\begin{array}{c}C T=28 \\
R X=3 \\
M R I=0 \\
U S=0\end{array}$ \\
\hline Utero-vaginal & 26 & 879 & 821 & 58 & 0 & 0 & 26 & 863 & 16 & $\begin{array}{c}C T=25 \\
R X=0 \\
M R I=1 \\
U S=0\end{array}$ \\
\hline Prostate & 11 & 268 & 59 & 0 & 209 & 1 & 10 & 268 & 0 & $\begin{array}{c}C T=0 \\
R X=0 \\
M R I=0 \\
U S=11\end{array}$ \\
\hline Breast & 6 & 84 & 84 & 0 & 0 & 0 & 6 & 84 & 0 & $\begin{array}{c}C T=6 \\
R X=0 \\
M R I=0 \\
U S=0\end{array}$ \\
\hline Anus & 10 & 38 & 36 & 2 & 0 & 0 & 10 & 82 & 2 & $\begin{array}{c}C T=8 \\
R X=1 \\
M R I=1 \\
U S=0\end{array}$ \\
\hline Rectum & 4 & 4 & 4 & 0 & 0 & 0 & 4 & 3 & 1 & $\begin{array}{c}C T=4 \\
R X=0 \\
M R I=0 \\
U S=0\end{array}$ \\
\hline Head and neck & 6 & 36 & 36 & 0 & 0 & 0 & 6 & 30 & 6 & $\begin{array}{c}C T=6 \\
R X=0 \\
M R I=0 \\
U S=0\end{array}$ \\
\hline Bile ducts & 4 & 7 & 7 & 0 & 0 & 1 & 3 & 4 & 3 & $\begin{array}{c}C T=3 \\
R X=1 \\
M R I=0 \\
U S=0\end{array}$ \\
\hline Esophagus & 9 & 35 & 35 & 0 & 0 & 3 & 6 & 23 & 12 & $\begin{array}{c}C T=6 \\
R X=3 \\
M R I=0 \\
U S=0\end{array}$ \\
\hline Skin & 16 & 206 & 206 & 0 & 0 & 6 & 10 & 203 & 3 & $\begin{array}{c}C T=10 \\
R X=3 \\
M R I=0 \\
U S=3\end{array}$ \\
\hline $\begin{array}{l}\text { Choroidal } \\
\text { Melanoma }\end{array}$ & 5 & 115 & 0 & 0 & 115 & 3 & 2 & 115 & 0 & $\begin{array}{c}C T=0 \\
R X=0 \\
M R I=0 \\
U S=5\end{array}$ \\
\hline BRONCHUS & 9 & 36 & 36 & 0 & 0 & 4 & 5 & 21 & 15 & $\begin{array}{c}C T=5 \\
R X=4 \\
M R I=0 \\
U S=0\end{array}$ \\
\hline
\end{tabular}

$R T$ - radiotherapy, $L D R$ - low-dose-rate, $H D R$ - high-dose-rate, $P D R$ - pulsed-dose-rate 
ommend brachytherapy as first-line options for low- and selected intermediate-risk prostate cancer. Furthermore, brachytherapy may be used to administer a boost after external beam radiotherapy for intermediate or high-risk cases $[12,13,14]$. Randomized comparative data with external beam radiotherapy or brachytherapy for prostate cancer are awaited.

Breast cancer was treated with brachytherapy in relatively few Italian radiation oncology centres, and usually served to administer a boost after whole breast irradiation (WBI). However, many centres preferred electrons or photons for boost delivery because of their easy administration, even though multi-catheter HDR brachytherapy that was reportedly associated with less irradiation exposure to organs at risk and fewer long-term side effects than photon radiotherapy [15]. Very few Italian radiation oncology centres use multi-catheter brachytherapy for accelerated partial breast irradiation (APBI) in low-risk patients, even though phase II studies demonstrated it was safe and effective $[16,17,18]$, and a large prospective phase III study showed that 5-year outcomes were not inferior to WBI [19]. To aid in patient selection, recommendations for brachytherapy as boost after WBI [20] and as APBI [21] were drawn up to encourage its clinical practice.

In some Italian centres, brachytherapy was performed to treat tumours in the oesophagus, bronchus, and rectum in curative or palliative settings, with the aim of improving quality of life and controlling symptoms. As an alternative to stent placement for managing esophageal cancer-related dysphagia, brachytherapy was highly effective and relatively safe [22]. As palliative care, it efficiently overcame the breathing difficulties that were caused by endobronchial tumour obstruction. Furthermore, it played a limited but specific role as curative treatment in selected cases of early endobronchial disease and in post-operative treatment of small residual peribronchial disease. Depending on the location of the lesion, brachytherapy, which is fast, inexpensive, and easy to perform on an outpatient basis, was treatment of choice in some cases [23]. HDR endorectal brachytherapy was delivered as a neoadjuvant treatment for patients with operable rectal tumors or to improve local control of newly diagnosed rectal cancer in patients who had already undergone pelvic radiation [24].

Skin cancers were treated with brachytherapy in some Italian centres, even though it has a limited role in disease managment, given modern plastic surgery techniques. Brachytherapy has long been reserved as second-line therapy for patients with surgical contraindications or as adjuvant therapy for resected, high-risk cutaneous lesions. Newer electronic surface brachytherapy devices and a mould technique might extend its use, particularly when surgery risks being demolitive [25].

Although radiotherapy plays a major role in the treatment of choroidal melanoma [26], brachytherapy was used in very few Italian centres due to lack of skilled staff. As an alternative to enuclation, brachytherapy with 126-RU or 125-Iodine (depending on lesion thickness) preserves the eye and vision, and offers excellent local control rates and cosmetic outcomes. Indeed, no survival differences emerged between patients treated with
125-Iodine eye plaque brachytherapy and those who underwent surgical enucleation [26].

In head and neck cancers, brachytherapy increases the tumor-received dose and spares surrounding structures like the tempro-mandibular joint, salivary gland, and mandible. Short duration of overall treatment reduces the risk of tumor repopulation, decreases integral dose, and presents the best dose conformity for the tumor. Despite these advantages, brachytherapy was offered by only six Italian radiation oncology centres, apparently because skilled staff and multi-disciplinary teams were missing. It is to be hoped that the recent GEC ESTRO recommendations about brachytherapy for head and neck cancers [27] will soon encourage its implementation in this field. Working in this direction is the European COBRA project on head and neck cancer [28]. A multi-centre group (consortium) is validating the newest technologies and developing measures to set up a decision support system (DSS), in order to tailor treatment for individual patients. The concept of personalized medicine derives from observations that although many patients may benefit from a specific treatment, certain other subgroups do not respond and may even incur a worse outcome due, for example, to treatment-related toxicity.

\section{Conclusions}

This is the first snapshot of current brachytherapy use in Italy. Findings from this national survey will aid in defining goals for future policy developments and cooperation in brachytherapy education and practice. Brachytherapy equipment was often under-used, due to a lack of skilled radiatian oncologists, multi-disciplinary teams, and supporting staff. It is to be hoped the survey results will lead to improvements, so that all patients will receive brachytherapy whenever it is the most appropriate treatment for them. In the future, brachytherapy may be even more individualized thanks to the development of the large database COBRA, which will set-up multi-factorial prediction models.

\section{Disclosure}

The authors report no conflict of interest.

\section{References}

1. Lambin P1, Van Stiphout RG, Starmans MH et al. Predicting outcomes in radiation oncology multifactorial decision support systems. Nat Rev Clin Oncol 2013; 10: 27-40.

2. Hoskin PJ, Bownes P. Innovative technologies in radiation therapy: brachytherapy. Semin Radiat Oncol 2006; 16: 209-217.

3. Cattari G, Delmastro E, Bresciani $S$ et al. Survey on gynecological cancer treatment by Piedmont, Liguria, and Valle d'Aosta group of AIRO (Italian Association of Radiation Oncology). J Contemp Brachytherapy 2016; 8: 128-134.

4. Guedea F1, Ellison T, Venselaar J et al. Overview of brachytherapy resources in Europe: a survey of patterns of care study for brachytherapy in Europe. Radiother Oncol 2007; 82: 50-54.

5. Guedea F, Ventura M, Mazeron JJ et al. Patterns of care for brachytherapy in Europe: facilities and resources in brachytherapy in the European area. Brachytherapy 2008; 7 : 223-230. 
6. Venselaar JL, Slotman BJ, Guedea F et al. Patterns of care study for brachytherapy: results of the questionnaire for the years 2002 and 2007 in The Netherlands. J Contemp Brachytherapy 2010; 2: 145-152.

7. Castelnau-Marchand P, Chargari C, Haie-Meder C et al. Image-guided adaptive brachytherapy in locally advanced cervical cancer: recent advances and perspectives. Curr Opin Oncol 2016; 28: 419-428.

8. Schernberg A, Balleyguier C, Dumas I et al. Diffusion-weighted MRI in image-guided adaptive brachytherapy: Tumor delineation feasibility study and comparison with GEC-ESTRO guidelines. Brachytherapy 2017; 16: 956-963.

9. Colombo N, Creutzberg C, Amant F et al. ESMO-ESGO-ESTRO Consensus Conference on Endometrial Cancer: diagnosis, treatment and follow-up. Ann Oncol 2016; 27: 16-41.

10. Perrucci E, Lancellotta V, Bini V et al. Recurrences and toxicity after adjuvant vaginal brachytherapy in Stage I-II endometrial cancer: A monoinstitutional experience. Brachytherapy 2016; 15: 177-184.

11. Han K, Mylosevic M, Fyles A et al. Trends in the utilization of brachytherapy in cervical cancer in the United States. Int J Radiat Oncol Biol Phys 2013; 87: 111-119.

12. Hoskin PJ, Colombo A, Henry A et al. GEC/ESTRO recommendations on high dose rate afterloading brachytherapy for localised prostate cancer: an update. Radiother Oncol 2013; 107: 325-332.

13. Ferrer M, Suárez JF, Guedea F et al. Health-related quality of life 2 years after treatment with radical prostatectomy, prostate brachytherapy, or external beam radiotherapy in patients with clinically localized prostate cancer. Int J Radiat Oncol Biol Phys 2008; 72: 421-432.

14. Martinez AA, Demanes DJ, Galalae R et al. Ten-year results in 1577 intermediate/high risk prostate cancer patients treated with external beam radiation therapy and hypofractionated high-dose-rate brachytherapy boost. Brachytherapy 2009; 8: 109.

15. Terheyden MM, Melchert C, Kovács G. External beam boost versus interstitial high-dose-rate brachytherapy boost in the adjuvant radiotherapy following breast-conserving therapy in early-stage breast cancer: a dosimetric comparison. J Contemp Brachytherapy 2016; 8: 294-300.

16. Aristei C, Maranzano E, Lancellotta V et al. Partial breast irradiation with interstitial multi-catheter high-dose-rate brachytherapy. Long-term results of a phase II prospective study. Radiother Oncol 2017; 124: 208-213.

17. Strnad V, Hildebrandt G, Pötter R et al. Accelerated partial breast irradiation: 5-year results of the German-Austrian multicenter phase II trial using interstitial multicatheter brachytherapy alone after breast-conserving surgery. Int J Radiat Oncol Biol Phys 2011; 80: 17-24.

18. Budrukkar A, Gurram L, Upreti RR et al. Clinical outcomes of prospectively treated 140 women with early stage breast cancer using accelerated partial breast irradiation with 3-dimensional computerized tomography-based brachytherapy. Radiother Oncol 2015; 115: 349-354.

19. Strnad V, Ott OJ, Hildebrandt G et al. 5-year results of accelerated partial breast irradiation using sole interstitial multicatheter brachytherapy versus whole-breast irradiation with boost after breast-conserving surgery for low-risk invasive and in-situ carcinoma of the female breast: a randomised, phase 3, non-inferiority trial. Lancet 2016; 387: 229-238.

20. Polo A, Polgár C, Hannoun-Levi JM et al. Risk factors and state-of-the-art indications for boost irradiation in invasive breast carcinoma. Brachytherapy 2017; 16: 552-564.

21. Polgár C, Van Limbergen E, Pötter R et al. Patient selection for accelerated partial-breast irradiation (APBI) after breast-conserving surgery: recommendations of the Groupe
Européen de Curiethérapie-European Society for Therapeutic Radiology and Oncology (GEC-ESTRO) breast cancer working group based on clinical evidence (2009). Radiother Oncol 2010; 94: 264-273.

22. Fuccio L, Mandolesi D, Farioli A et al. Brachytherapy for the palliation of dysphagia owing to esophageal cancer: A systematic review and meta-analysis of prospective studies. Radiother Oncol 2017; 122: 332-339.

23. Skowronek J. Brachytherapy in the treatment of lung cancer a valuable solution. J Contemp Brachytherapy 2015; 7: 297-311.

24. Vuong TE, Devic S, PhD. High-dose-rate pre-operative endorectal brachytherapy for patients with rectal cancer. J Contemp Brachytherapy 2015; 7: 183-188.

25. Alam M, Nanda S, Mittal BB et al. The use of brachytherapy in the treatment of nonmelanoma skin cancer: a review. J Am Acad Dermatol 2011; 65: 377-388.

26. Collaborative Ocular Melanoma Study Group. The COMS randomized trial of iodine 125 brachytherapy for choroidal melanoma: V. Twelve-year mortality rates and prognostic factors: COMS report No 28. Arch Ophthalmol 2006; 124: 1684-1693.

27. Kovács G, Martinez-Monge R, Budrukkar A et al. GEC-ESTRO ACROP recommendations for head \& neck brachytherapy in squamous cell carcinomas: 1st update - Improvement by cross sectional imaging-based treatment planning and stepping source technology. Radiother Oncol 2017; 122: 248-254.

28. Tagliaferri L, Kovács G, Autorino R et al. ENT COBRA (Consortium for Brachytherapy Data Analysis): interdisciplinary standardized data collection system for head and neck patients treated with interventional radiotherapy (brachytherapy). J Contemp Brachytherapy 2016; 8: 336-343. 